\title{
The Possible Protective Role of Melatonin on Doxorubicin Induced Cardiomyopathy of Adult Male Albino Rats
}

\section{Original Article}

\author{
Rania I. Yassien and Amira F. Elsaid \\ Department of Histology, Faculty of Medicine, Menoufia University, Menoufia, Egypt
}

\begin{abstract}
Introduction: Doxorubicin is one of the major antitumor treatment. The essential limiting factor of using this drug is the production of cardiotoxicity. However, melatonin is a powerful antioxidant that may protect the heart.

Aim: This study was aimed to study possible protective role of melatonin in adult male albino rats following doxorubicin administration

Material and Method: In this study, 40 adult male albino rats were used. They were divided into four groups (10 rats for each): control group, Melatonin group, Doxorubicin group and Doxorubicin \& Melatonin group. Heart specimens were obtained at the end and processed.

Results: Light studies showed degenerative changes. Some fibers showed dark acidophilic cytoplasm and pyknotic nuclei. Apoptosis were detected where the nuclei varying from peripheral condensation of chromatin up to pyknosis, confirmed with positively caspase-3 activity. Dilatation of the vessels with mononuclear cellular infiltrations and deposited collagen fibers were seen. Ultrastructural examination showed disarrangement of the sarcomeres, disruption of microfilaments and Z- line, the number and size of mitochondria apparently increased, dilated SER and T tubules were also noticed. The presence of oval shaped cells (Telocyte) with thin long processes (Telopodes) were detected.

Conclusion: From this study, it was concluded that, melatonin markedly suppressed cardiomyopathy induced by doxorubicin.
\end{abstract}

Key Words: Doxorubicin, melatonin, cardiac muscle, telocyte, caspase-3, ultrastructure.

Received: 5 October 2016, Accepted: 31 December 2016

Corresponding Author: Rania I. Yassien, Tel.: +2 01028073793, E-mail: raniayassien@yahoo.com

ISSN: 1110-0559, March 2017, Vol. 40, No. 1

\section{INTRODUCTION}

Doxorubicin which is from anthracycline group widely used as an effective antineoplastic agent, as therapy of several of malignancies, including leukemia, lymphoma, and solid tumors. Cumulative dosedependent cardiotoxicity of this drug limited its clinical use, which may cause irreversible and severe effect of cardiomyopathy ${ }^{[1]}$.

The specific mechanisms of doxorubicin (DOX) induced cardiotoxicity are complex and although decades of research on this drug, remain unclear. Different mechanisms may play a role in the effects induced by DOX, including suppression of protein synthesis and nucleic acid formation, lysosomal deformities, changes in adrenergic function, mitochondrial abnormalities, changed sarcolemmal $\mathrm{Ca} 2+$ transport, calcium overload and energy metabolism disorders may lead to lipid peroxidation in myocardial fibers; and an imbalance of myocardial electrolytes ${ }^{[2]}$. Effects of DOX may be attributed to Oxidative/nitrosative stress $^{[3]}$. production of reactive oxygen species (ROS) may be the cause of effects of DOX or through induction of nitric oxide synthases (NOS), leading to nitric oxide (NO) formation. It has been shown that, DOX treatment in vivo leads to cardiomyocytes apoptosis ${ }^{[4]}$, and increased levels of cleaved caspase-3 in DOX-treated animal's myocytes ${ }^{[5]}$.

An alternative mechanism to explain Dox toxicity reported by Ito H. et al. ${ }^{[6]}$ is that, Dox selectively suppresses the cardiac specific program of gene expression ${ }^{[7]}$. Production of iron $(\mathrm{Fe} 2+)$ free radical complex is another mechanism of DOX-induced damage ${ }^{[8]}$. Molecular oxygen is reduced to superoxide anion $\left(\mathrm{O}^{-2}-2\right)$ that is converted to other forms of reactive oxygen species. ROS reacts with lipid, protein and other cellular components to cause 
damage to cell membrane and mitochondria of the heart muscle fibers ${ }^{[1]}$.

These free radicals may then cause injury to the heart, which has a relatively low level of superoxide dismutase (SOD) and catalase (antioxidant enzymes). Others studies propose that the mechanism of DOX-induced heart apoptosis is dependent on the activation of tumor suppressor $\mathrm{p} 53^{[9,10]}$.

The main secretory product of the pineal gland is Melatonin (MEL). The pineal gland is inactive in the day time but it is activated and starts to actively produce melatonin in the darkness. MEL participates in circadian rhythm regulation and has main role in anti aging processes $^{[11,12]}$.

Melatonin works as a free radical scavenger of $\mathrm{OH}$, superoxide anions peroxyl radicals and also as a powerful antioxidant ${ }^{[13]}$.actually, MEL was shown to be twice as powerful as vitamin $\mathrm{E}$ in removing peroxyl radicals ${ }^{[14]}$ and it is 5 and 14 times more effective in scavenging hydroxyl radicals than glutathione and mannitol, respectively ${ }^{[15]}$. Unlike the limited distribution of vitamin $\mathrm{C}$ or vitamin $\mathrm{E}$, MEL distributes nearly in all subcellular compartments due to its solubility in both water and lipids. As such, it can move into membrane of the cell easily and enter cardiac cells to eliminate free radicals in situ. Additionally, MEL have effects via MEL1a receptors in the myocytes ${ }^{[16,11,17]}$.

Therefore, this study was designed to estimate the protective effects of melatonin on cardiotoxicity induced by doxorubicin.

\section{MATERIAL AND METHODS}

Fourty adult male albino rats of average weight $150-250$ gm were used in this study. The animals obtained from breeding animal house, Faculty of Medicine, Menoufia University.

Animals were housed in the animal laboratory of Menoufia faculty of medicine. Strict care and cleaning measures were utilized to keep the animal in a normal healthy condition; the animals were put in animal cages under the prevailing atmospheric conditions and also were fed to standard diet and liberal supply of tap water. They were kept under a photoperiod of $12 \mathrm{~h}$ light: $12 \mathrm{~h}$ darkness, in controlled conditions of temperature $\left(2024-{ }^{\circ} \mathrm{C}\right)$. All ethical protocols for animal treatment were followed. The experimental protocol was accepted by the Ethical Committee of Menoufia Faculty of Medicine.

\section{Used drugs}

- Doxorubicin: 5ml vial and each contain $10 \mathrm{mg}$ were obtained from EGYDRUG Company, Egypt (10 mg/ $5 \mathrm{ml}$ vial).
- Melatonin: $3 \mathrm{mg}$ tablets ( $3 \mathrm{mg} /$ tablet) were obtained from BIOVERA EGYPT Company.

\section{Experimental procedure:}

Rats were divided into four groups, included 10 rats for each as follows:

\section{Group I (Control group)}

The first 5 rats received intraperitoneal injection of $0.9 \% \mathrm{NaCl}$ for 4 days as vehicle for DOX. The other 5 rats received intraperitoneally $2.5 \%$ ethanol for 15 days as vehicle for melatonin. They were sacrificed at the same time as the corresponding experimental group.

\section{Group II (Melatonin treated group)}

Melatonin (dissolved in 2.5\% concentrated ethanol) was administered intraperitoneally at a dose of $6 \mathrm{mg} / \mathrm{kg} /$ day for 15 days $^{[18]}$.

\section{Group III (Doxorubicin treated group)}

Doxorubicin (dissolved in $0.9 \% \mathrm{NaCl}$ ) was administered intraperitoneally at a dose of $3 \mathrm{mg} / \mathrm{kg} /$ day for 4 days ${ }^{[18]}$.

\section{Group IV (Doxorubicin and Melatonin treated group)}

It received doxorubicin and melatonin combination treatment. Melatonin was started 1 day before doxorubicin administration. When the two drugs were administrated in combination, melatonin was given $3 \mathrm{hrs}$ before each doxorubicin injection (melatonin was injected at 10:00 am and doxorubicin at 1:00pm). The two drugs were given for 4 days and then melatonin was continued to be given for another 10 days with the same doses and method mentioned before $^{[18]}$.

At the end of the experiment, cardiac perfusion by saline was done under an aesthesia for the histological and immunohistochemical examination of the cardiac muscle. After perfusion, the heart was removed and cardiac tissue pieces of the left ventricle were obtained for:

\section{Histological study:}

Paraffin sections of $5 \mu \mathrm{m}$ were obtained and stained with hematoxylin and eosin (H\&E) to show the histological details and Masson's trichrome stain to detect the collagen fibers $^{[19]}$.

\section{Immunohistochemical study:}

Caspase-3: sections were subjected to staining with the primary rabbit polyclonal anti-caspase-3 antibody (Thermo Scientific, Lab Vision, USA) ${ }^{[20]}$. 


\section{Ultrastructure Study:}

Cardiac samples from 4 rats in each group were processed for electron microscopy. A small portion of the left ventricle near the apex was excised, rapidly (within 1 min) and minced into $1 \times 1 \mathrm{~mm}^{2}$ pieces, primary fixed in $3 \%$ glutraldehyde and $0.1 \mathrm{M}$ phosphate buffer at $\mathrm{pH} 7.4$, postfixed in osmium tetraoxide, processed and embedded in epon. Semithin sections ( $1 \mu \mathrm{m}$ thick) stained with toluidine blue and examined by light microscope. Ultrathin sections (5080- nm thick) were contrasted with uranyl acetate and lead citrate and then examined with the transmission electron microscope (Seo-Russia) in Tanta E.M Center at faculty of medicine Tanta University ${ }^{[21,22]}$.

\section{RESULTS}

Histological, Histochemical and Ultrastructural Results

\section{A- Group I (Control)}

Cardiac muscle fibers appeared as branching, anastomosing cylinders of uniform diameters and arranged in groups. They showed acidophilic sarcoplasm with central elongated vesicular nuclei, Flat deeply stained nuclei of fibroblast of C.T. endomysium were also seen (Figs. 1\&2). In Masson trichrome stained sections, they showed few collagen fibers deposition between the cardiac muscle fibers (Fig. 3). Immunostaining for caspase-3 showed -ve reaction (Fig. 4)

Electron microscopic examination revealed nucleus with dispersed hetrochromatin. Cytoplasm showed alternates dark bands (A) which bisected by $\mathrm{H}$ zone and light bands (I) which bisected by $\mathrm{Z}$ line. Mitochondria (M) with abundant cristae are distributed between myofibrils. The intercalated discs were seen (Fig. 5).

\section{B- Group II (Melatonin group):}

Light microscopic examination revealed Cardiac muscle fibers with acidophilic sarcoplasm and central elongated vesicular nuclei almost similar to control (Fig. 6).

\section{C-Group III (Doxorubicin group)}

Light microscopic examination revealed Pale longitudinal cardiac muscle fibers. Some fibers showed dark acidophilic cytoplasm and pyknotic nuclei. Wide interstitium contained haemoarrge between muscle fibers was seen. The mononuclear inflammatory cells were seen between muscle fibers (Fig. 7). Areas of fibers loss and mononuclear cellular infiltrations in wide interstitium were detected. Also, rupture the wall of blood vessels and vacuoles in the wall of other vessels were seen (Fig. 8).

The Masson trichrome stained section showed excessive collagen fibers deposition inbetween cardiac muscle fibers and around congested blood vessels (Fig.9). Immunostaining for caspase -3 showed strong +ve reaction in the affected cardiac muscle fibers (Fig.10).

Electron microscopic examination showed an apparent increase in the size and number of mitochondria and in mitochondrial matrix density (Fig. 11). Degenerative changes in mitochondria in the form of mitochondrial matrix lysis and loss of the cristae were also noticed (Fig. 12). Microfilaments disruption, thin myofibril and degeneration of intercalated disc were detected (Figs. 11- 13). Some areas showed disrupted Z-line (Figs. 11\&13). However, some sections showed thick $Z$ lines (Fig. 12\& 14). Dilated $T$ tubules\& SER at $Z$ lines were noticed (Figs. 13\& 16). In addition, small nuclei with irregular nuclear membrane and clumps of heterochromatin were noticed (Fig. 11) Wide interstitium containing inflammtory cell and fibroblast were detected (Figs. 11, $13 \&$ 15). In the wide interstitium between cardiomyocytes, the presence of oval shaped cell (Telocyte) with little amount of cytoplasm and nucleus with heterochromatin clumps was noticed. Telocyte showed thin long processes (Telopodes) with dilated portion (podoms). Telocyte surrounded another cell most probably progenitor cell. Telopodes surrounded part of cytoplasm containing most probably cell debris from degeneration of myofibrils (Figs. 14 -17).

\section{C-Group IV (doxorubicin and melatonin)}

Light microscopic examination revealed appearance more or less similar to control group. Branching, anastomosing cylinders of myocytes with minimal amount of collagen fibers in C.T. interstitium was seen (Figs. 18 and 19). Immunostaining reaction for caspase-3 showed-ve reaction (Fig. 20).

Electron microscopic examination showed cardiac muscle fibers of appearance more or less similar to control group. Dilated cisternae of SER \& $\mathrm{T}$ tubules were noticed (Fig. 21). 


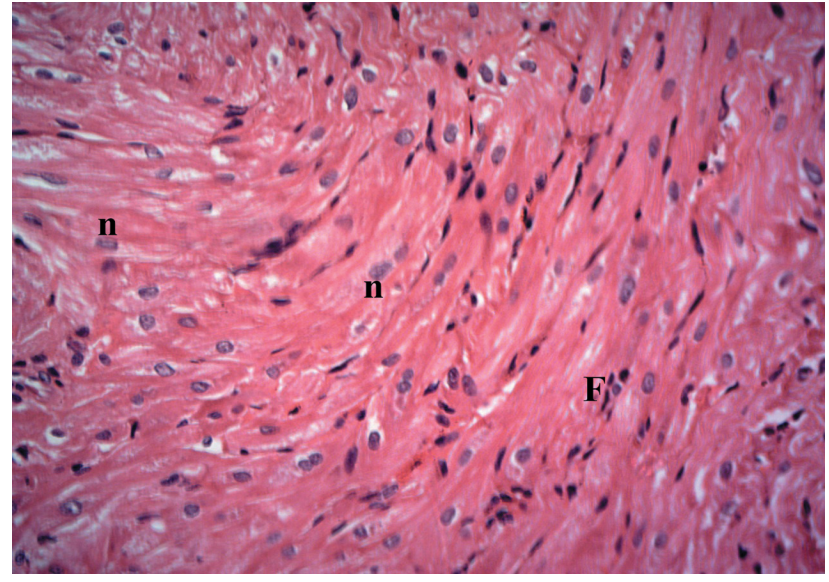

Fig. 1: A section of rat's myocardium of group I (control) showing branching and anastomosing cardiac muscle fibers with acidophilic sarcoplasm and central elongated vesicular nuclei (n). Flat dark nuclei of fibroblasts of C.T. endomysium were seen (F). $H \&$ E X 200

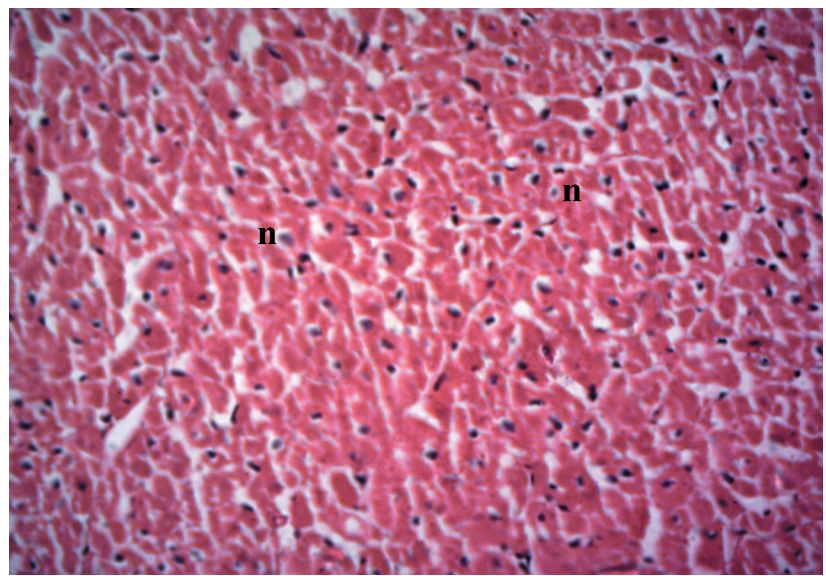

Fig. 2: Transverse section of rat's myocardium of group I (control) showing cardiac muscle fibers with acidophilic sarcoplasm and some revealed central vesicular nuclei (n). H\&E X200

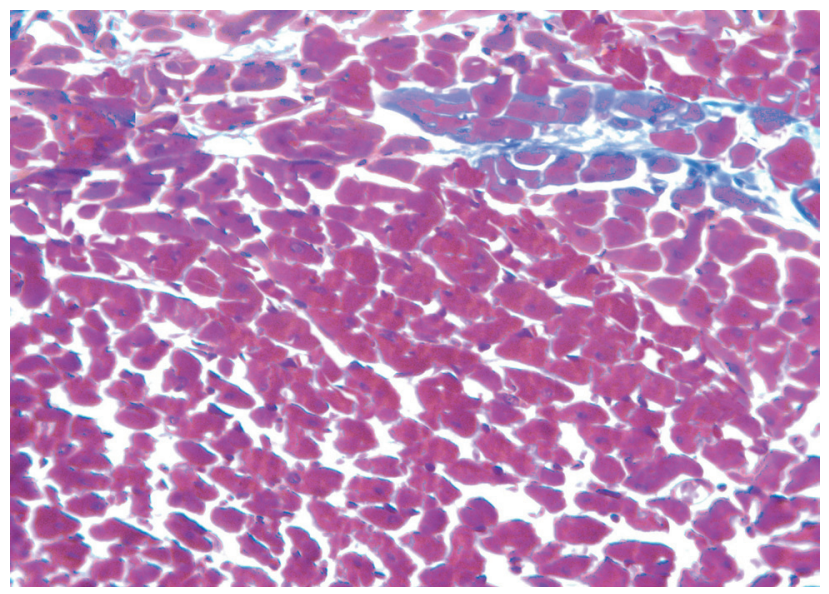

Fig. 3: A section of rat's myocardium of group I (control) showing few collagen fibers inbetween the cardiac muscle fibers. M.T X400

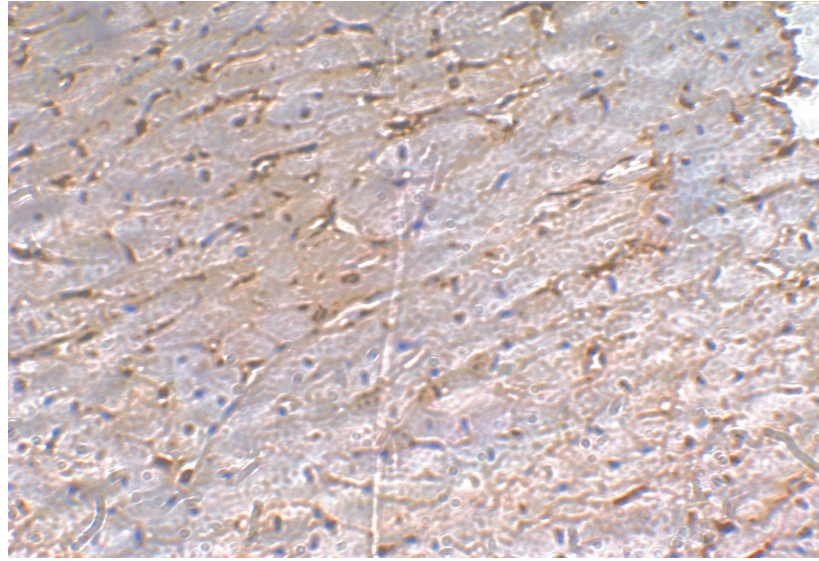

Fig. 4: A section of rat's myocardium of group I ( control) showing -ve immunostaining for caspase-3. Caspase-3 X400

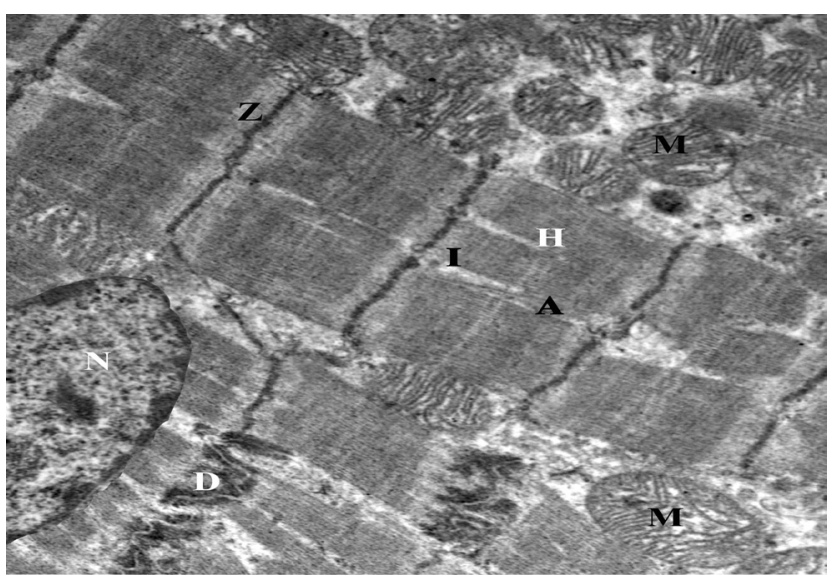

Fig. 5: An electron micrograph of part of rat's myocyte of group I (control) showing part of nucleus with dispersed hetrochromatin (N). Cytoplasm with myofibrils showing alternates dark bands (A) which bisected by $(\mathrm{H})$ zone \& light bands (I) which bisected by $\mathrm{Z}$ line. Mitochondria $(\mathrm{M})$ with abundant cristae are distributed between myofibrils. Notice: the intercalated discs (D). X X4000

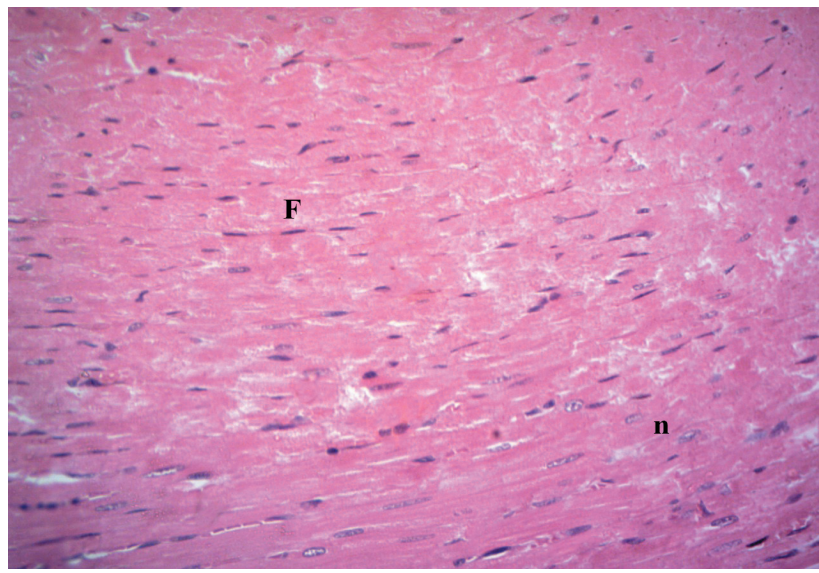

Fig. 6: A section of rat's myocardium of group II (melatonin) showing cardiac muscle fibers with acidophilic sarcoplasm and central oval vesicular nuclei (n). Flat dark nuclei of fibroblasts are seen $(F)$. 


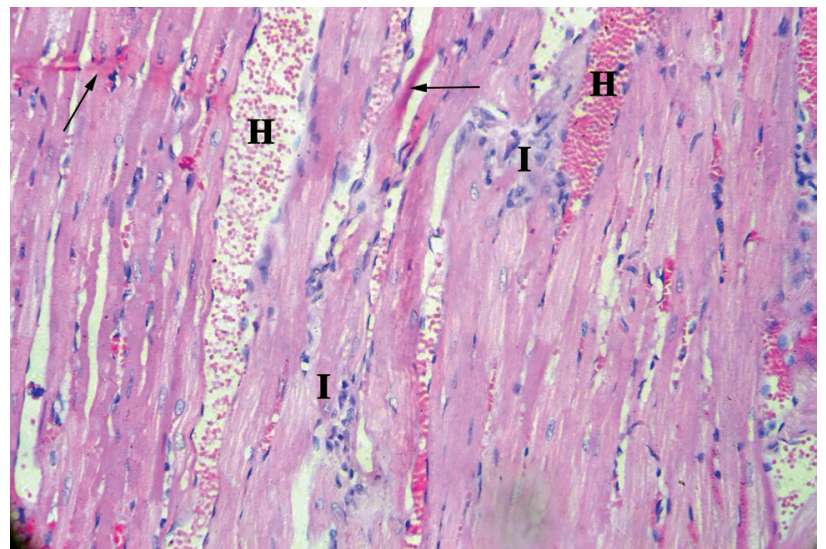

Fig. 7: A section of rat's myocardium of group III (doxo) showing pale longitudinal cardiac muscle fibers. Some fibers reveal dark acidophilic cytoplasm and pyknotic nuclei (arrow). Wide interstitium containing RBCS $(\mathrm{H})$ is seen between muscle fibers. Notice: the mononuclear inflammatory cells (I) between muscle fibers.

H\&E X200

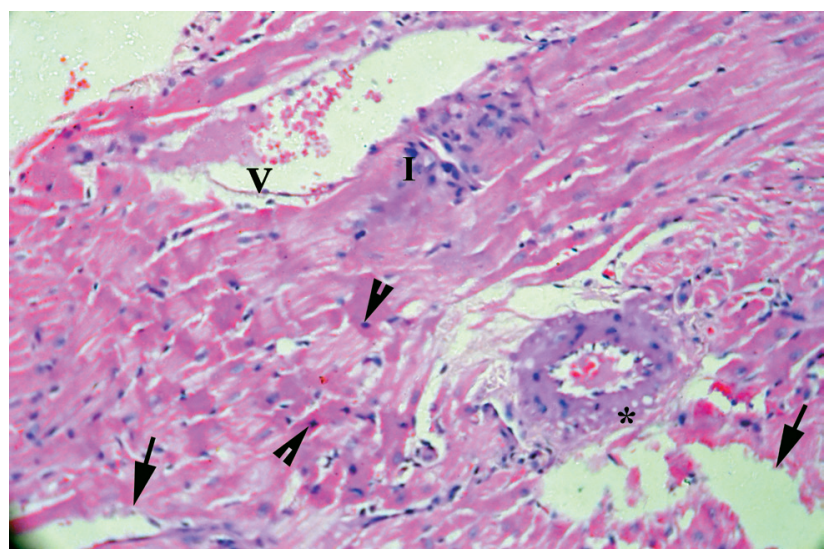

Fig. 8: A section of rat's myocardium of group III (doxo) showing area of fibers loss (arrow). Some fibers with dark cytoplasm \& pyknotic nuclei are seen (arrowheads). Mononuclear cellular infiltrations (I) and rupture the wall of blood vessels (V) are detected in wide interstitium. Notice: vacuoles $(*)$ in the wall of blood vessels.

$\mathrm{H} \& \mathrm{E}$ X400

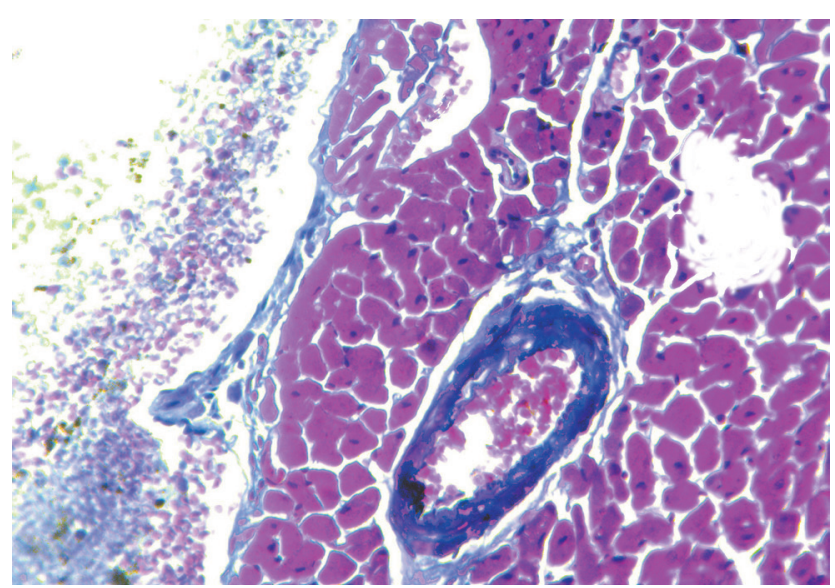

Fig. 9: A section of rat's myocardium of group III (doxo) showing marked deposition of collagen fibers inbetween the cardiac muscle fibers and around congested blood vessel. M.T X400

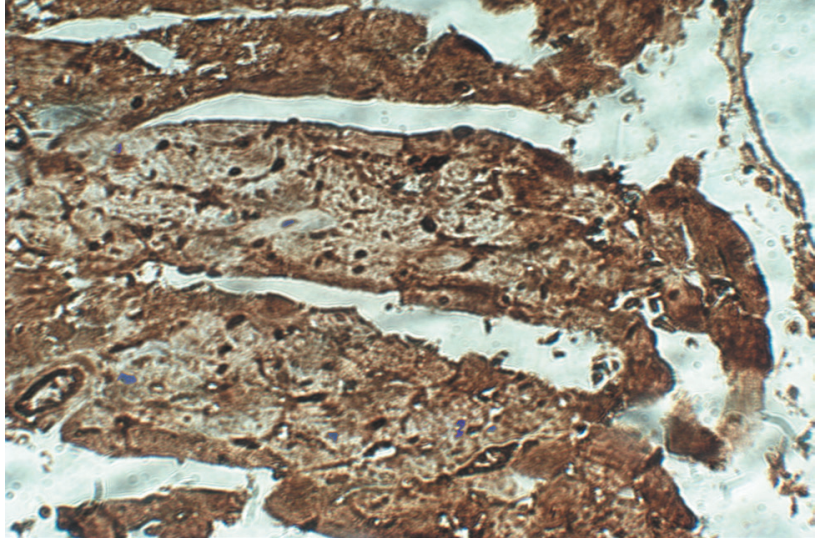

Fig. 10: A section of rat's myocardium of group III (doxo) showing strong +ve immunostaining for caspase-3 in some cells. caspase- 3 X400

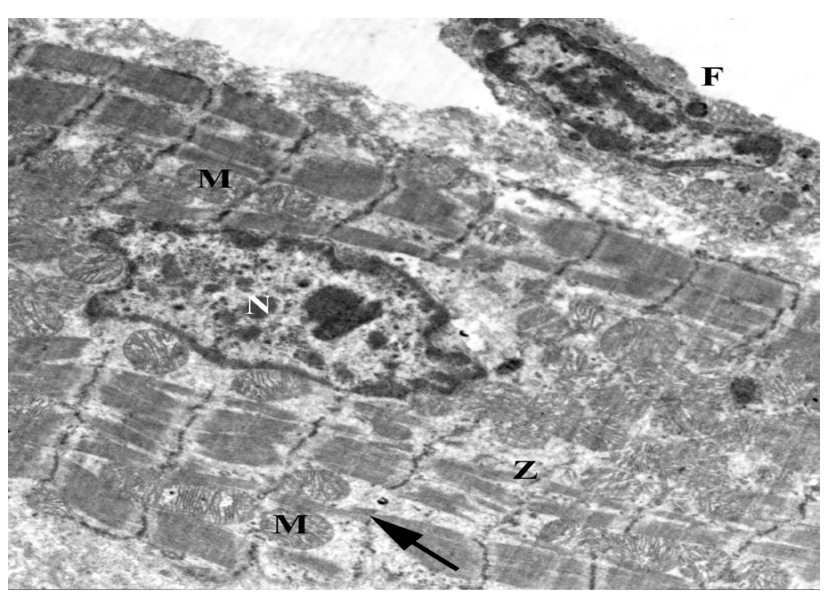

Fig. 11: An electronmicrograph of part of cardiac myocytes of group III (doxo) showing nucleus of cardiomyocyte with irregular nuclear envelope and clumps of heterochromatin(N). The cytoplasm shows thin myofibrils (arrow), numerous mitochondria(M) and disrupted $\mathrm{Z}$ line. Notice: The nucleus of fibroblast (F) in interstitium.

X2000

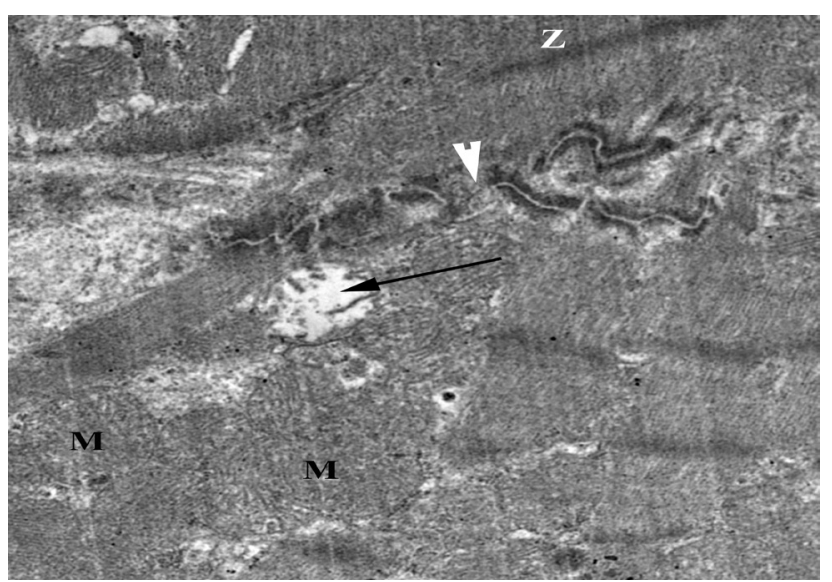

Fig. 12: An electronmicrograph of rat's myocardium of group III (doxo) showing mitochondria with lost cristae leaving empty space (arrow). Other mitochondria are aggregated together (M). Thick $\mathrm{Z}$ lines, disorganization of intercalated disc (arrow head) are seen.

X4000 


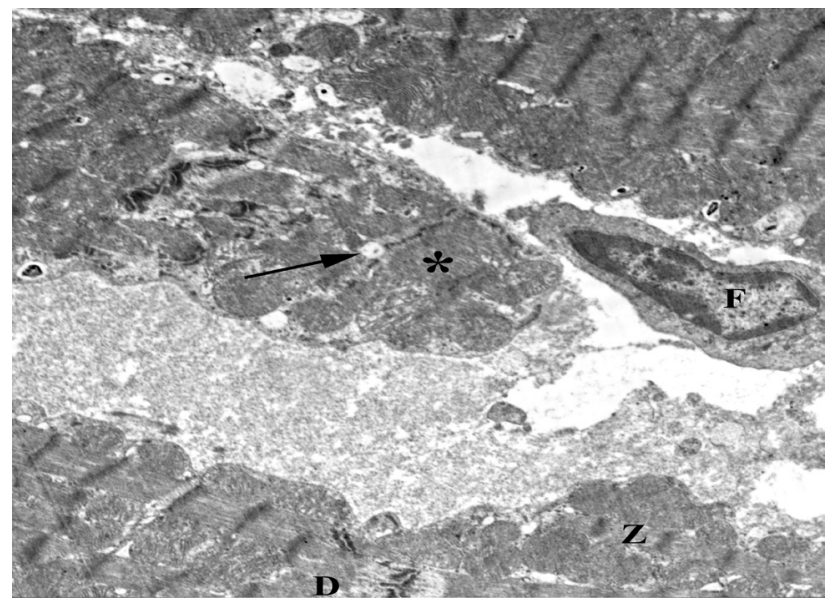

Fig. 13: An electronmicrograph of rat's myocardium of group III (doxo) showing myofibrils lose their architecture $\left({ }^{*}\right)$, dilated SER $\& \mathrm{~T}$ tubules (arrow) disrupted $\mathrm{Z}$ line \& intercalated discs (D). Notice: wide interstitium containing fibroblast (F). $\quad$ X2000

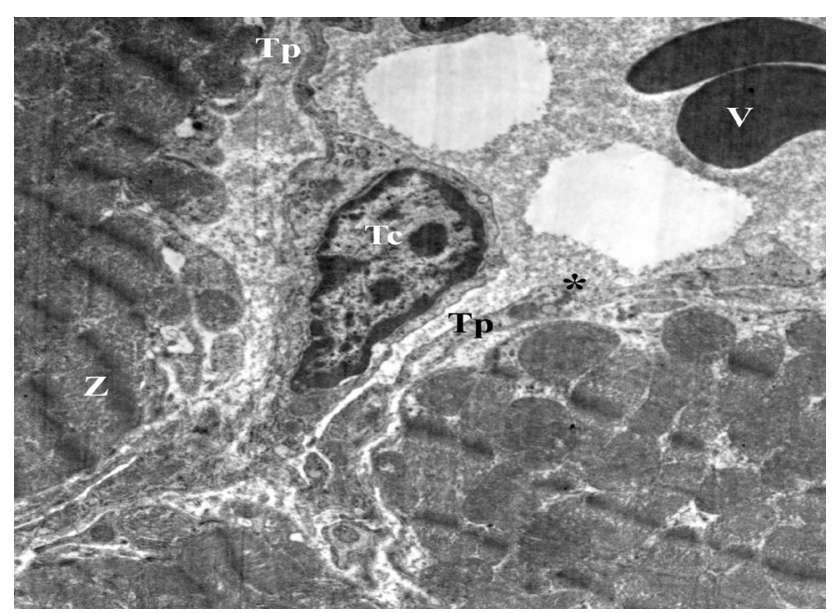

Fig. 14: An electronmicrograph of rat's myocardium of group III (doxo) showing wide interstitium containing telocyte (Tc) with its telopode $(\mathrm{Tp})$ which contain dilated segment podom $(*)$. Blood vessels (V) are also seen in the interstitium. Notice: Thick $\mathrm{Z}$ lines.

$\mathrm{X} 2000$

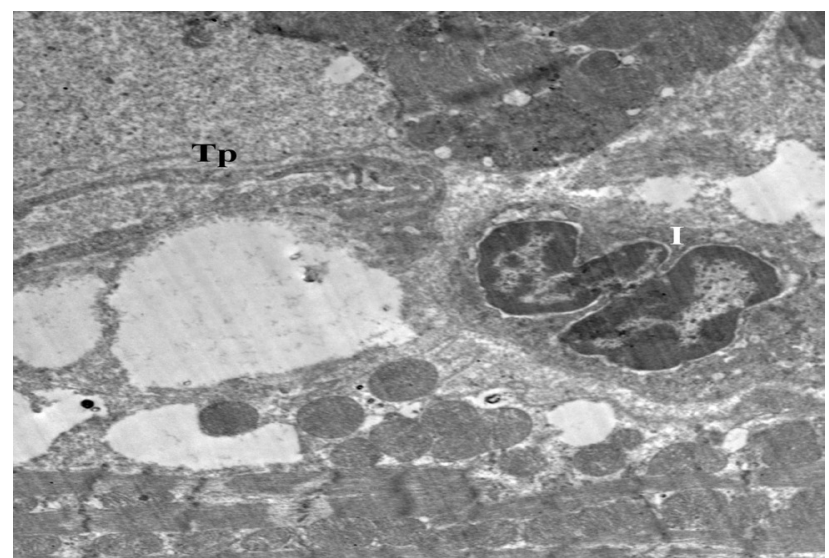

Fig. 15: An electronmicrograph of rat's myocardium of group III (doxo) showing telopodes (Tp) of telocyte near Inflammatory cells (I) and degenerated cardiac myocyte. Notice: dilated SER \& $\mathrm{T}$ tubules (arrow).

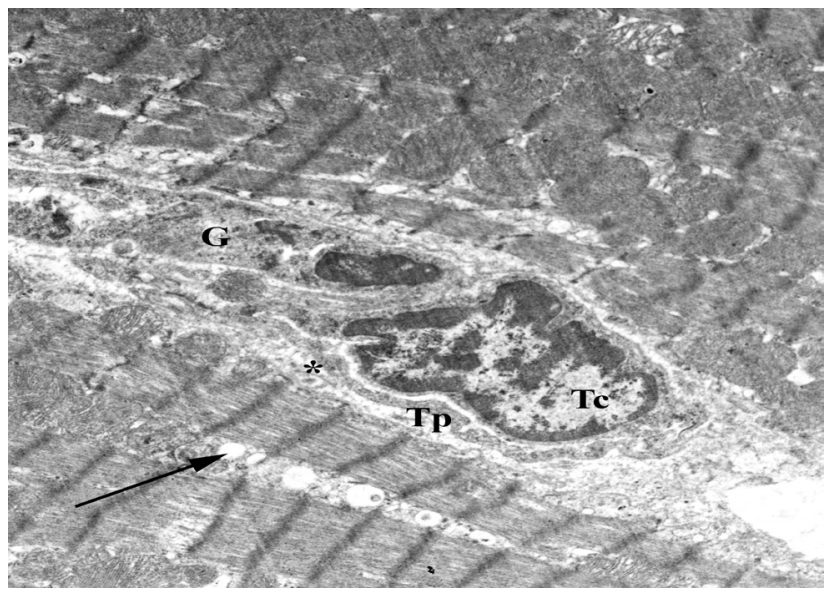

Fig 16: An electronmicrograph of rat's myocardium of group III (doxo) showing interstitium contain nucleus of telocyte (Tc) with irregular nuclear envelope, clumps of hetrochromatin and scanty cytoplasm. The telopodes $(\mathrm{Tp})$ with its podoms $(*)$ are seen. Telocyte surrounds another cell (G). Notice: dilated SER \& T Tubules (arrow).

$\mathrm{X} 2000$

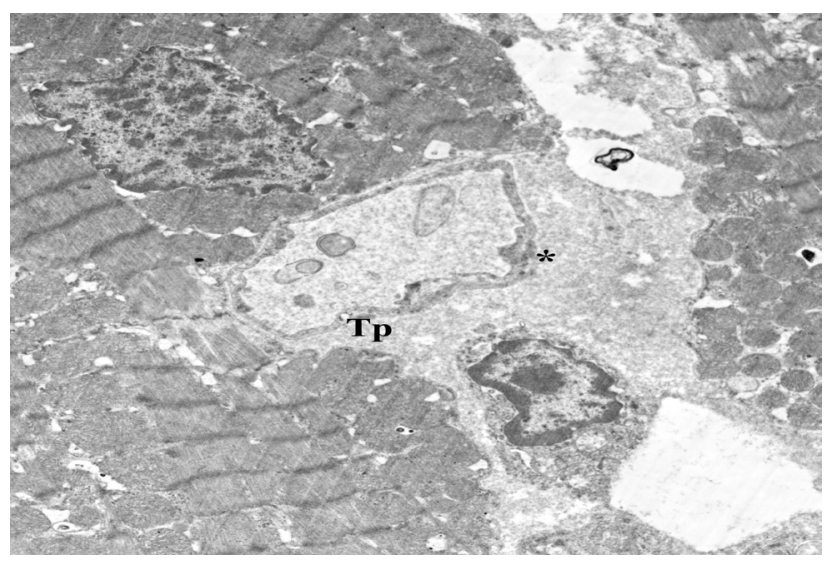

Fig 17: An electronmicrograph of rat's myocardium of group III (doxo) showing the telpods (Tp) with its dilated podoms $(*)$ surrounding part of cytoplasm. Tp surrounding cell debris from degeneration of myofibrils.

$\mathrm{X} 1500$

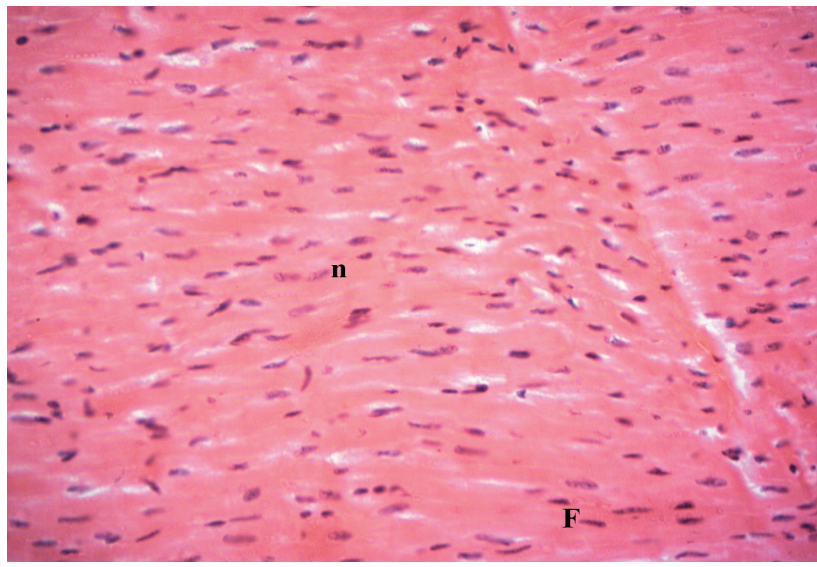

Fig. 18: A section of rat's myocardium of group IV (doxo and melatonin) showing the cardiac muscle fibers with appearance more or less similar to control. Note: vesicular nuclei (n) of cardiac muscle fiber \& Flat dark nuclei (F) of fibroblast of C.T. endomysium are seen.

$\mathrm{H} \& \mathrm{E}$ X200 


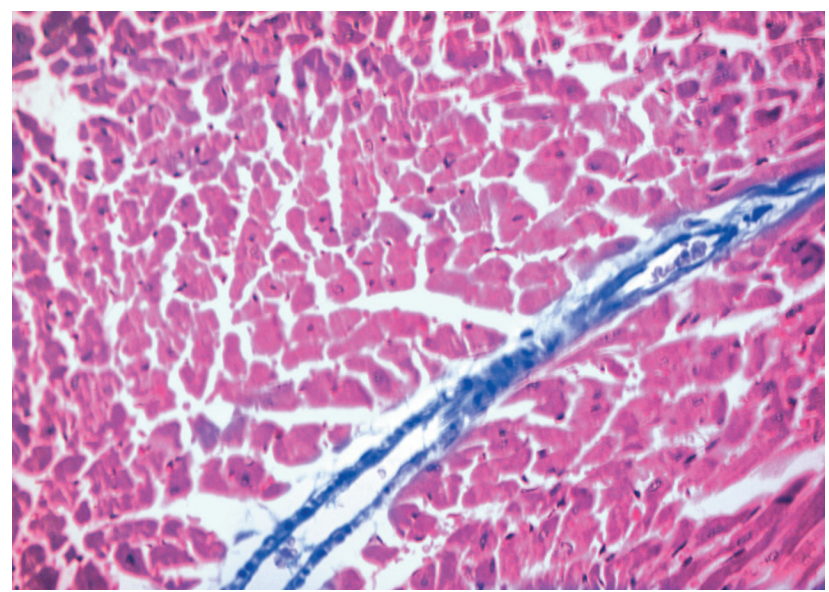

Fig. 19: A section of rat's myocardium of group IV (doxo and melatonin) showing minimal deposition of collagen fibers in the C.T. interstitium.

M.T X400

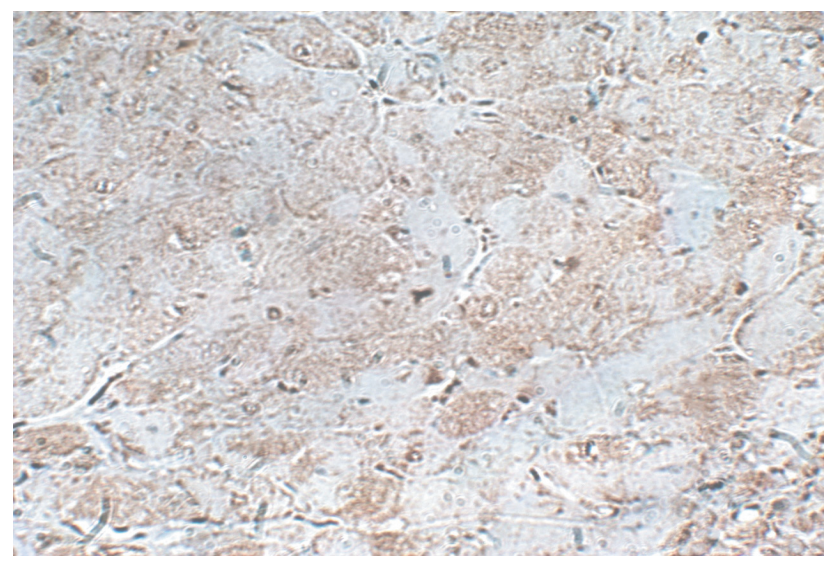

Fig. 20: A section of rat's myocardium of group IV (doxo and melatonin) showing -ve immunostaining reaction for caspase -3 .

caspase $-3 \mathrm{X} 400$

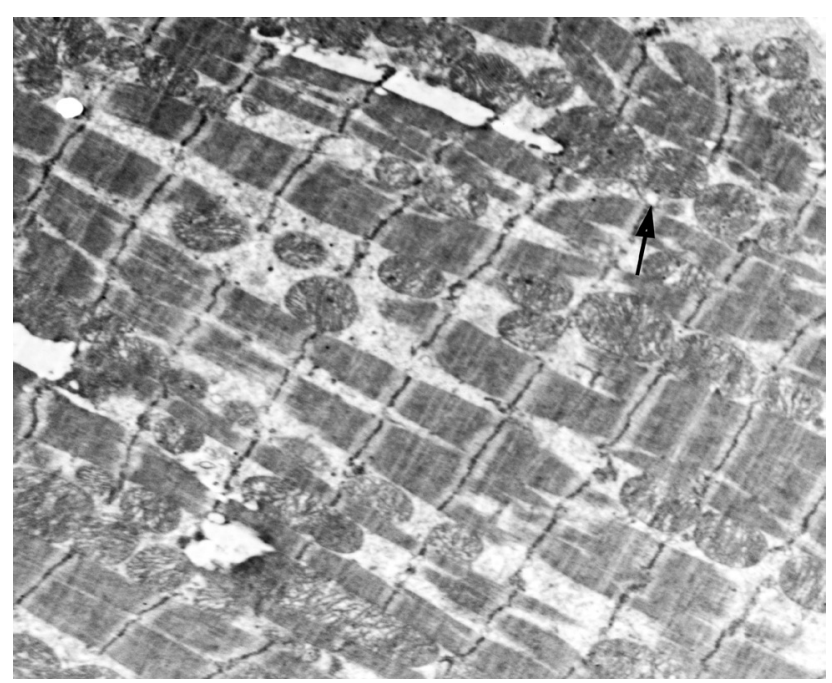

Fig.21: An electronmicrograph of rat's myocardium of group IV (doxo and melatonin) showing appearance more or less similar to control of cardiac muscle fibers are seen. Notice: Dilated SER \& T tubules (arrow).

X2000

\section{DISCUSSION}

Inspite of the antitumor effect of Doxorubicin, it had cardiotoxic effect by different mechanisms other than those mediating its antitumor activity. A concept which has raised hopes for protecting the heart without decreasing antitumor response ${ }^{[23]}$. After reviewing light and electron microscopic results, it was proved that doxorubicin had harmful effects on the structure of the myocardium and led to myocardial injury.

Light microscopic examination of the present study in DOX treated group revealed cytoplasmic vacuolation of some muscle fibers. These findings were in agreement with Liu et al. ${ }^{[1]]}$ and Pathan et al. ${ }^{[1]}$. Some fibers with dark cytoplasm and pyknotic nuclei and areas of fibers loss were seen. These results were confirmed with an apparent increase of caspase immunoreactivity of some muscle fibers in Doxo treated animals. This was confirmed by results of several investigators ${ }^{[5,24-26]}$.

Also, some investigators revealed the significance of the caspase-3- activated apoptotic pathway in the mechanism of DOX induced myocardial cell death. Furthermore, they stated that activated caspase is localized at the Z-line and therefore is able to cleave cardiac myofilaments directly ${ }^{[27,28]}$.

In the present study Dox treated group showed widening interstium, rupture of wall of blood vessels with area of hemorrhage between muscle fibers. Marked vascular dilatation was noticed; this coincided with the work of other authors who added that increased accumulated blood cells between the damaged cardiac myocytes were noticed ${ }^{[29]}$.

Inflammatory cellular infiltration was observed after doxorubicin treatment. These finding were coincided with other investigations ${ }^{[30,31]}$. Excessive deposition of collagen fibers in DOX treated group was seen. This may be due to lipid peroxidation caused by doxorubicin that stimulated collagen formation. ${ }^{[32,33]}$. Some scientists found that oxidative reactions directly stimulate procollagen Type1 gene expression which contributes to the development of collagen fibers ${ }^{[32]}$.

The previous light microscopic changes of Doxo group were confirmed by electron microscopy which showed disorganization of sarcomeres, myofibrillar degeneration with thinning of myofibrils bundle and empty spaces between them. Some fibers however, preserved normal fine structure. This result was in agreement with other researchers ${ }^{[7,34]}$.

Mitochondria of some myocytes of Doxo treated group appeared to have apparent small size or 
have broken cristae and lysis and fragmentation of mitochondrial matrix. Mitochondria were the primary target for Doxo cardiotoxoicity as they expressed unique enzyme on the inner membrane that is able to reduce anthracyclines to their semiquinone derivatives ${ }^{[7,34]}$.

Lipid peroxidation makes changes in the mitochondrial membrane permeability \&stability and then inhibits enzymatic activities that are important for oxidative phosphorylation and ATP production. Thus, the whole metabolic reactions decrease and this condition gradually lead to cell death ${ }^{[34]}$.

Mitochondria were the primary sites of energy production so mitochondrial injury would severely decrease the contractile function of cardiac myocytes by reducing energy metabolism ${ }^{[11]}$.

On the other hand, some myocytes in the present study have apparent increased number \&size of mitochondria. Some previous studies stated that the increase in the number and size of the mitochondria could be a compensatory adaptive mechanism of cells to supply the energy needed for all the reactions including the metabolic activity ${ }^{[18]}$.

Furthermore, the adjacent mitochondria might fuse and try to decrease intracellular reactive oxygen radical levels by reducing the consumption of oxygen. These findings seem to be in close relation to those appearing in the related literatures ${ }^{[35,36,37,38]}$. That explained that formation of megamitochondria was based on morphological and biochemical alterations in membranes of mitochondria.

In the doxorubicin-treated group, degenerative changes in cardiocytes with myofibrils loss, disrupted $\mathrm{Z}$ line and I bands were noticed. Many investigators revealed that, these ultrastructural changes may be related to doxorubicin interaction with actin myofilaments which is an essential component of the $\mathrm{Z}$ lines and thin filaments ${ }^{[18,39]}$.

Apparent thickened $\mathrm{Z}$ lines in some area in Doxo treated group in the present study was explained by Mariano ${ }^{[40]}$ who reported that doxorubicin caused actin polymerisation. On the other hand, $\mathrm{Z}$ lines appeared disrupted in other areas due to inhibition of protein synthesis and decrease in the level of cytoplasmic $\operatorname{actin}^{[40,41]}$. Disruption in intercalated disc could be detected. This resulted in disruption in transmission of contractile forces ${ }^{[18]}$.

The cytoplasmic vacuolization detected in doxorubicin treated animals could be attributed to sarcoplasmic reticulum and $\mathrm{T}$ tubules dilatation at $\mathrm{Z}$ line ${ }^{[24]}$. This was in harmony with other scientists who suggested that the dysfunction of the sarcoplasmic reticulum accelerated after the completion of Doxo treatment due to hydropic degeneration of their membranes ${ }^{[42]}$.

In Doxorubicin-treated group, it was noticed that, the presence of oval shaped cell with little amount of cytoplasm in the interstitium. Its nucleus contained heterochromatin clumps. Also, it had thin long processes with dilated portion. This interstitial Cajallike cells (ICLC), had been described for the first time by Hinescu and Popescu in $2005^{[43]}$. This study was then followed by an ascending trend of publications regarding the morphology, phenotype and distribution of myocardial ICLC in diverse species. Recently the new term 'telocytes' has been proposed for cells formerly known as ICLC, and the term 'telopodes' has been proposed for the prolongations of these cells. Telocytes are a distinct type of stromal cells described in the cardiac interstitium and termed 'telocytes' because of their long, slender processes (telopodes Tp) embracing the myocardial cells. The identification of these cells was based on ultrastructural criteria ${ }^{[44,45]}$.

The present study of Doxo treated group revealed telopodes surrounded other cells most probably progenitor cells. This was confirmed by other researches which stated that telocytes were present in subepicardial niche in adult rodents to guide myocardial precurors and played role in heart regeneration. Also, it had a stem cell nursing function in the cardiac stem cell niche. In this case, they formed three-dimensional network which direct and guard myocardial regeneration ${ }^{[44]}$. In our study telopodes surrounded part of cytoplasm contained most probably cell debris from degeneration of myofibrils. This coincided with other scientists who stated that telocyte improved the reconstruction of the $\mathrm{CT}$ network by decreasing myocardial fibrosis. Also, it increased vascularity by increased VEGF. Myocardial telocytes and telopodes were involved in intercellular signaling. They secreted small signal molecules and shed microvesicles \& exosomes that transfer macromolecules for repair of myocardial cells. So TCs might be key players in regeneration/repair of myocardium ${ }^{[46,48]}$.

As regards Doxorubicin-induced myocardial injury is known to have multiple mechanisms of action, most accepted one of them may be mediation of free radicals $(\mathrm{ROS})^{[4,48]}$. Also, Doxo- mediated alteration of calcium hameostasis has been suggested to be one of mechanisms of cardiotoxicity. Doxo accelerate the probability opening of sarcoplasmic reticulum calcium channels, inhibits $\mathrm{Na}+-\mathrm{Ca}^{2+}$ exchanger and this can cause calcium overload of sarcoplasm which led to membrane injury and apoptosis. Also, may render mitochondrial calcium overloading resulting in alteration of energy metabolism and generation of 
reactive oxygen species as explained by Waring ${ }^{[49]}$ and Kim et al. ${ }^{[50]}$.

In this study, the histological results of Doxomelatonin (group IV) showed light microscopic results more or less similar to control. It revealed -ve reaction of caspase -3 . This was in agreement with the previous findings of other investigators ${ }^{[11,51]}$. Electron microscopic examination revealed dilated cisterne of SER and T tubules.

In the present study, melatonin had its improvement activity through various mechanisms including its antiapoptotic and antioxidants effects ${ }^{[11,12]}$ to reduce the effects of free radicals. Furthermore, the concurrent treatment with melatonin might be led to inhibition of peroxidation of lipid. These results were also similar to the observation of some authors ${ }^{[51]}$.

\section{CONCLUSION}

In conclusion, from the present study it was cleared that melatonin treatment, before and in concurrent with doxorubicin, markedly attenuated DOX - induced cardiomyopathic changes and myocardial injury.

It was recommended to use melatonin in concurrent with doxorubicin in cancer treatment. This was based on the previous studies that proved that melatonin did not influence antitumor effect of Dox. So, the combined treatment of DOX and MEL made an effective and safe chemotherapeutic strategy.

\section{CONFLICT OF INTEREST}

There are no conflicts of interest

\section{REFERENCES}

1. Pathan RA, Singh BK, Pillai KK and Dubey $\mathrm{K}$ : Naproxen aggravates doxorubicin-induced cardiomyopathy in rats. Indian Journal of Pharmacology (2010) 42:44- 49.

2. Singal PK, Deally CMR and Weinberg LE: Subcellular effects of adriamycin in the heart: A concise review. J. Mol. Cell. Cardiol. (1987) 19: 817-28.

3. Mukhopadhyay P, Rajesh M, Batkai S, Kashiwaya Y, Hasko G and Liaudet L: Role of superoxide, nitric oxide and peroxynitrite in doxorubicin-induced cell death in vivo and in vitro. Am. J. Physiol. Heart Circ. Physiol. (2009) 296: H1466-83.
4. Childs AC, Phaneuf SL, Dirks AJ, Phillips T and Leeuwenburgh C: Doxorubicin treatment in vivo causes cytochrome c release and cardiomyocyte apoptosis - as well as increased mitochondrial efficiency - superoxide dismutase activity and Bcl-2: Bax. ratio. Cancer. Res. (2002) 62: 4592-8.

5. Ivanová M, Dovinová I, Okruhlicová L, Tribulová N, Šimončíková $P$, Barte-ková M, Vlkovičová $\mathrm{J}$ and Barančík M: Chronic cardiotoxicity of doxorubicin involves activation of myocardial and circulating matrix metalloproteinases in rats. Acta. Pharmacologica Sinica (2012) 33(4): 459- 69.

6. Ito $\mathrm{H}$, Miller SC, Billingham ME, Akimoto $\mathrm{H}$, Torti SV, Wade R, Gahlmann R, Lyons G, Kedes L and Torto FM: Doxorubicin selectively inhibits muscle gene expression in cardiac muscle cells in vivo and in vitro. Proc. Natl. Acad. Sci. USA (1990) 87(11): 4275-9.

7. Rahman A, Alam M, Rao S, Cai L, Clark LT, Shafiq $S$ and Siddiqui MA: Differential effects of doxorubicin on atrial natriuretic peptide expression in vivo and in vitro. Biol. Res. (2001) 34 (3 -4): 195- 206

8. Malisza KL and Hasinoff B: Production of hydroxyl radical by iron (III)-anthraquinone complexes through self-reduction and through reductive activation by the xanthine oxidase/ hypoxanthine system. Arch. Biochem. Biophys. (1995) 321: 51- 60.

9. Regula KM and Kirshenbaum LA: P53 activates the mitochondrial death pathway and apoptosis of ventricular myocytes independent of de novo gene transcription. J. Mol. Cell. Cardiol. (2001) 33(8): 1435- 45.

10. Liu X, Chua CC, Gao J, Chen Z, Landy CL, Hamdy $\mathrm{R}$ and Chua BH: Pifithrin- $\alpha$ protects against doxorubicin-induced apoptosis and acute cardiotoxicity in mice. Am. J. Physiol. Heart Circ. Physiol. (2004) 286(3): H933 -9.

11. Liu X, Chen Z, Chua CC, Ma YS, Youngberg GA, Hamdy R and Chua BH: Melatonin as an effective protector against doxorubicin-induced cardiotoxicity. Am. J Physiol. Heart Circ. Physiol. (2002) 283(1): H254 -63.

12. Bilginoğlu A, Aydın D, Ozsoy S and Aygün H: Protective effect of melatonin on adriamycin- 
induced cardiotoxicity in rats. Turk. Kardiyol. Dern. Ars. (2014) 42(3): 265- 73.

13. Reiter R, Tang L, Garcia JJ and Munoz-Hoyos A: Pharmacological actions of melatonin in oxygen radical pathophysiology. Life Sci (1997) 60(25): $2255-71$

14. Pieri C, Marra M, Moroni F, Recchioni R and Marcheselli F: Melatonin: a peroxyl radical scavenger more effective than vitamin E. Life Sci (1994) 55(15): PL271 -6.

15. Hardeland R, Reiter RJ, Poeggeler B and Tan DX: The significance of the metabolism of the neurohormone melatonin: antioxidative protection and formation of bioactive substances. Neurosci Biobehav Rev. (1993) 17(3): 347 -57.

16. Dubocovich ML: Melatonin receptors: are there multiple subtypes?. Trends Pharmacol. Sci (1995) 16(2): $50-6$

17. Alfaro Y, Delgado G, Cárabez A, Anguiano B and Aceves C: Iodine and doxorubicin, a good combination for mammary cancer treatment. Mol Cancer (2013) 12:45.

18. Balli E, Mete UO, Tuli A, Tap O and Kaya $\mathrm{M}$ : Effect of melatonin on the cardiotoxicity of doxorubicin. Histol. Histopathol. (2004) 19(4): $1101-8$

19. Suvarna SK, Layton C, Bancroft JD: Bancroft's Theory and practice of histological techniques. 7th ed. Churchill Livingstone 2013; 173- 212.

20. Sanii S, Saffar H, Tabriz HM, Qorbani M, Haghpanah V and Tavangar SM: Expression of matrix metalloproteinase-2 - but not caspase-3 - facilitates distinction between benign and malignant thyroid follicular neoplasms. Asian Pac. J. Cancer Prev. (2012) 13: 2175-2178.

21. Oberley TD, Swanlund JM, Zhang HJ and Kregel KC: Aging results in increased autophagy of mitochondria and protein nitration in rat hepatocytes following heat stress. J. Histochem. Cytochem. (2008) 56(6): 61527-

22. Mohamed AAK, Khalil S, Nossier NS and Khalil MS: The Protective Role of Alpha-Lipoic Acid Against Doxorubicin - Induced Cardiotoxicity in Male Albino Rats (A Light and Transmission
Electron Microscopy Study). Egypt. J. Histol. (2009) 32(1): 227 -234.

23. Minotti G, Menna P, Salvatorelli E, Cairo G and Gianni L: Anthracyclines: molecular advances and pharmacologic developments in antitumor activity and cardiotoxicity. Pharmacol. Rev. (2004) 56: 185- 229.

24. Lushnikova EL, Klinnikova MG, Molodykh OP and Nepomnyashchikh LM: Ultrastructural criteria of cardiomyocyte regeneratory and plastic insufficiency in anthracyline cardiomyopathy. Bull. Exp. Biol. Med. (2005) 139(4): 472- 6.

25. Jang YM, Kendaiah S, Drew B, Phillips T, Selman C, Julian D and Leeuwenburgh C: Doxorubicin treatment in vivo activates caspase-12 mediated cardiac apoptosis in both male and female rats. FEBS Lett. (2004) 577(3): 483 -90.

26. Kalivendi SV, Konorev EA, Cunningham S, Vanamala SK, Kaji EH, Joseph $J$ and Kalyanaraman B: Doxorubicin activates nuclear factor of activated T-lymphocytes and Fas ligand transcription: role of mitochondrial reactive oxygen species and calcium. Biochem. J. (2005) 389(2): $527-39$.

27. Moretti A, Weig HJ, Ott T, Seyfarth M, Holthoff HP, Grewe D, Gillitzer A, Bott-Flugel L, Schomig A, Ungerer $M$ and Laugwitz KL: Essential myosin light chain as a target for caspase - 3 in failing myocardium. Proc. Natl. Acad. Sci. USA (2002) 99(18): 11860-11865.

28. Kostin S, Pool L, Elsässer A, Hein S, Drexler HC, Arnon E, Hayakawa Y, Zimmermann R, Bauer E, Klövekorn WP and Schaper J: Myocytes die by multiple mechanisms in failing human hearts. Circ. Res. (2003) 92(7): 715- 24.

29. Moustafa A and Shalaby A: Impact of trimetazidine on doxorubicin-induced acute cardiotoxicity in mice: A biochemical and electron microscopic study. Egypt. J. Histol. (2006) 9(1): 125 -136.

30. Saad SY, Najjar TA and Al-Rikabi AC: The preventive role of deferoxamine against acute doxorubicin-induced cardiac renal and hepatic toxicity in rats. Pharmacol. Res. (2001) 43(3): $211-8$.

31. El-Sayyad HI, Ismail MF, Shalaby FM, Abou-ElMagd RF, Gaur RL, Fernando A, Raj MHG and Ouhtit A: Histopathological effects of cisplatin, doxorubicin and 5-flurouracil (5-FU) on the liver 
of male albino rats. Int. J. Biol. Sci. (2009) 5(5): 466- 473 .

32. Parola M, Pinzani M, Casini A, Albano E, Poli G, Gentilini A, Gentilini $P$ and Dianzani MU: Stimulation of lipid peroxidation or 4-hydroxynonenal treatment increases procollagen alpha 1 (I) gene expression in human liver fatstoring cells. Biochem. Biophys. Res. Commun. (1993) 194(3): 1044 -50.

33. Poli $G$ and Parola $M$ : Oxidative damage and fibrogenesis. Free Radic. Biol. Med. (1997) 22: 287- 305.

34. Lai $\mathrm{R}$, Long $\mathrm{Y}$, Li $\mathrm{Q}$, Zhang $\mathrm{X}$ and Rong $\mathrm{T}$ : Oxidative stress markers may not be early markers of doxorubicin-induced cardiotoxicity in rabbits. Exp. Ther. Med. (2011) 2(5): 947- 950.

35. Matsuhashi T, Liu X, Karbowski M, Wozniak M, Antosiewicz $\mathrm{J}$ and Wakabayashi T: Role of free radicals in the mechanism of the hydrazineinduced formation of megamitochondria. Free Radic. Biol. Med. (1997) 23: 285- 293.

36. Wakabayashi T, Adachi K, Matsuhashi T, Wozniak M, Antosiewicz J and Karbowsky M: Suppression of the formation of megamitochondria by scavengers for free radicals. Mol. Aspects. Med. (1997) 18: s51-s56.

37. Wakabayashi T. Megamitochondria formationphysiology and pathology. J. Cell. Mol. Med. (2002) 6: 497- 538.

38. Zhou S, Starkov A, Froberg MK, Leino RL and Wallace KB: Cumulative and irreversible cardiac mitochondrial dysfunction induced by doxorubicin. Cancer Res. (2001) 61(2): 771- 7.

39. Zeidan Q, Strauss M, Porras N and Anselmi G: Differential long-term subcellular responses in heart and liver to adriamycin stress. J. Submicrosc Cytol. Pathol. (2002) 34: 315- 321.

40. Mariano R, Gonzalez B and Lewis W: Cardiac actin interactions with doxorubicin in vitro. Exp. Mol. Pathol. (1986) 44(1): 7- 13.

41. Lewis W and Gonzalez B: Anthracycline effects on actin and actin-containing thin filaments in cultured neonatal rat myocardial cells. Lab. Invest. (1986) 54: $416-423$.
42. Chugun A, Temma K, Oyamada T, Suzuki N, Kamiya Y, Hara Y, Sasaki T, Kondo H and Akera T: Doxorubicin - induced late cardiotoxicity: delayed impairment of $\mathrm{Ca} 2+-$ handling mechanisms in the sarcoplasmic reticulum in the rat. Can. J. Physiol. Pharmacol. (2000) 78(4): 329- 38.

43. Hinescu ME and Popescu LM: Interstitial Cajallike cells (ICLC) in human atrial myocardium. J. Cell. Mol. Med. (2005) 9(4): 972- 5.

44. [Kostin S: Myocardial telocytes: a specific new cellular entity. J Cell Mol Med. (2010) 14(7): 1917-1921.

45. Mandache E, Gherghiceanu M, Macarie C, Kostin $\mathrm{S}$ and Popescu LM: Telocytes in human isolated atrial amyloidosis: ultrastructural remodelling. J. Cell. Mol. Med. (2010) 14(12): 2739- 47.

46. Popescu LM, Manole E, Serboiu CS, Manole CG, Suciu LC, Gherghiceanu M and Popescu BO: Identification of telocytes in skeletal muscle interstitium: implication for muscle regeneration. J. Cell Mol. Med. (2011) 15(6): 1379- 92.

47. Zhao B, Liao Z, Chen S, Yuan Z, Yilin C, Lee KK, Qi X, Shen X, Zheng X, Quinn T and Cai $\mathrm{D}$ : Intramyocardial transplantation of cardiac telocytes decreases myocardial infarction and improves post-infarcted cardiac function in rats. J. Cell Mol. Med. (2014) 18(5): 780 -9.

48. Kumar D and Jugdutt BI: Apoptosis and oxidants in the heart. J. Lab. Clin. Med. (2003) 142(5): 288- 97.

49. Waring, P: Redox active calcium ion channels, cell death. Arch. Biochem. Biophys. (2005) 434(1): $33-42$.

50. Kim SY, Kim SJ, Kim BJ, Rah SY, Chung SM, Im MJ and Kim UH: Doxorubicin - induced reactive oxygen species generation and intracellular $\mathrm{Ca} 2+$ increase are reciprocally modulated in rat cardiomyocytes. Exp. Mol. Med. (2006) 38(5): $535-45$.

51. Dziegiel $P$, Jethon Z, Suder E, Sopel M, Rabczyński J, Surowiak P and Zabel M: Role of exogenous melatonin in reducing the cardiotoxic effect of daunorubicin and doxorubicin in the rat. Exp. Toxicol. Pathol. (2002) 53(6): 433 -9. 
الملخص العربى

الدور الوقائي المحتمل لماده الميلاتونين على قلب الفأر الذكر الأبيض البالغ تحت تأثير عقار

رانيا ياسين وأميرة فهمي

\section{قسم علم الأنسجة ـ كلية الطب - جامعة المنوفية ــ المنوفية ـ مصر}

المقدمة: اجري هذا البحث لدر اسة التغير ات الهستولوجية و التركيبية الدقيقة والهستوكيمائية المناعية في قلب الفار الابيض البالغ الغئ

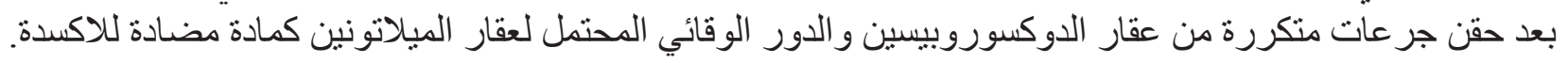

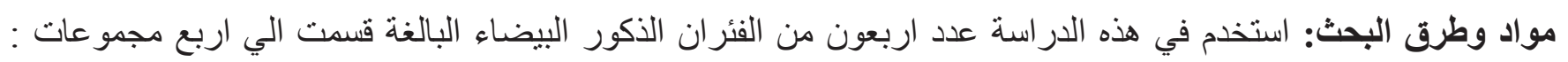

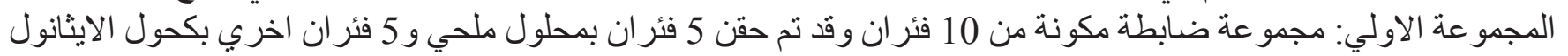

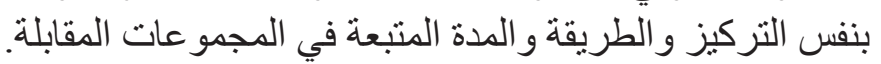

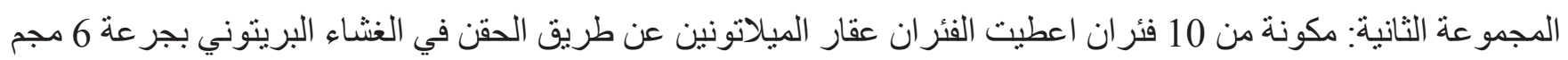

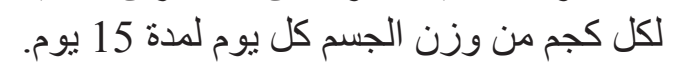
المجموعة الثالثة:مكونة من 10فئر ان اعطيت الحيو انات عقار الدوكسوروبيسين عن طريق الحقن في الغشاء البريتوني بجر عة

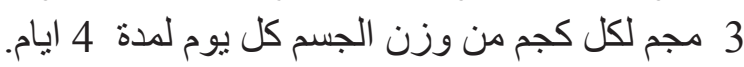

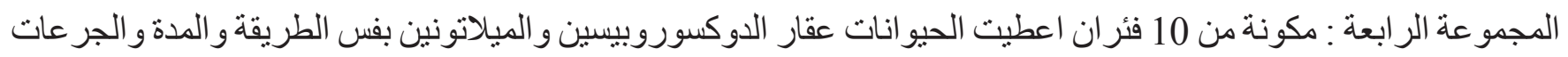

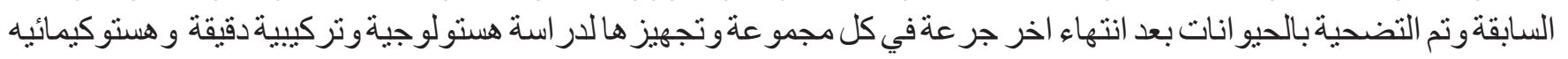

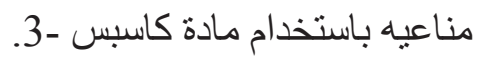

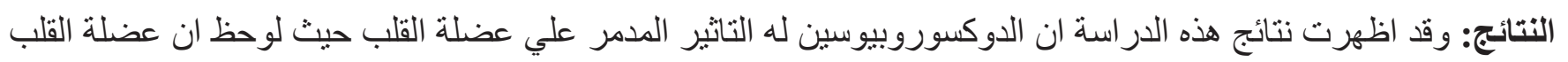

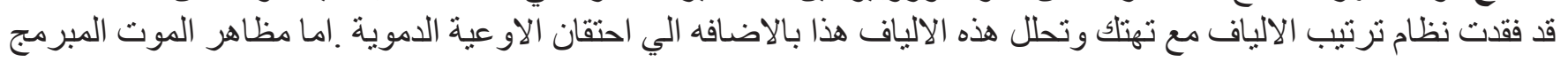

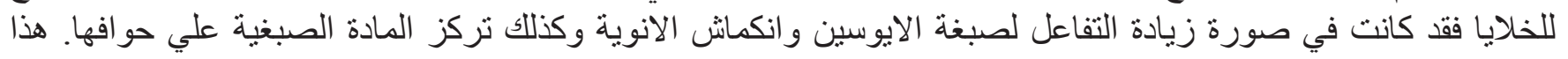

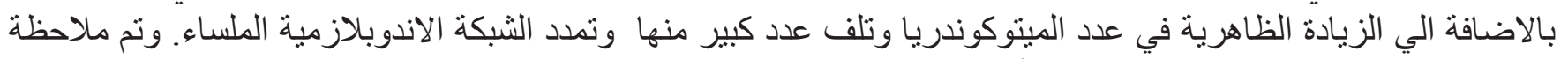

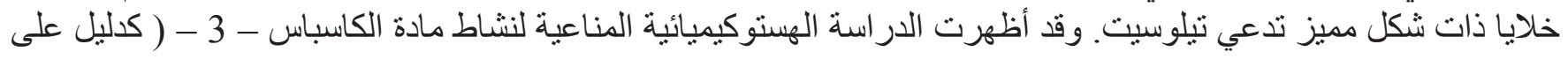

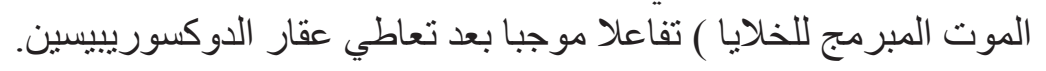

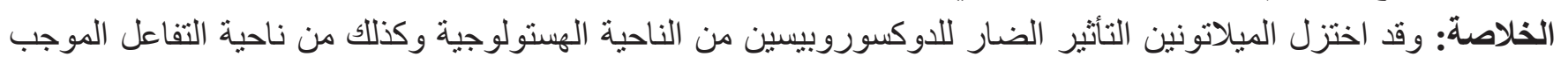

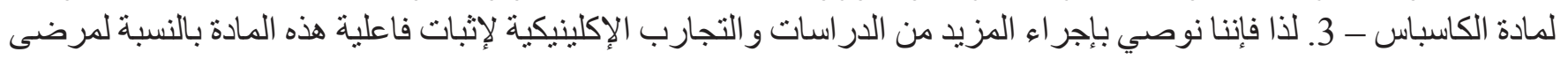
السرطان. 